\title{
New Faces in New Places: The Changing Geography of American Immigration
}

\author{
Edited by \\ Douglas S. Massey \\ New York, Russell Sage Foundation, 2008. \\ ISBN: 978-0-87154-586-2 \\ Price: $\$ 42.50$. 370 pages. \\ Bali Ram \\ Adjunct Research Professor \\ Department of Sociology and Anthropology \\ Carleton University \\ Ottawa, Ontario, Canada \\ E-mail: bali.ram@statcan.gc.ca
}

This edited volume is about the determinants and consequences of geographic dispersion of immigrants in the United States that began during the 1990s and continued into the $21^{\text {st }}$ century. Editor Douglas S. Massey, Henry G. Bryant Professor of Sociology and Public Affairs at the Woodrow Wilson School, is one of the most distinguished sociologist-demographers today. In this volume, Massey brings together an impressive collection of quantitative and qualitative studies, which is somewhat uncommon in demographic literature.

This book begins with an introductory chapter by Hirschman and Massey, which sets the stage for the chapters that follow, in addition to presenting an excellent overview of the volume. The remainder of the volume is divided into two parts. The first part shows clearly that although the majority of new immigrants still settle in the traditional gateway cities such as New York, Los Angeles, Chicago, Houston and Miami, there has been an increasing move to new destinations in smaller towns, suburbs and rural areas since the 1990s. The diversification of geographic destination is experienced by all immigrant groups, but is most pronounced among Mexicans/Hispanics.

The authors of the first part of the book describe and explain the emerging patterns of immigrant settlement. They focus on various reasons why new immigrants have been moving away from gateway cities on the West and East Coasts to smaller towns, suburbs and rural areas in the Midwest and South.

They point toward globalization, international economic competition, and industrial restructuring as the major driving forces behind these patterns, although not rejecting the hypothesis that most new immigrants follow the path 
of their ethnic predecessors by moving into established immigrants communities. During the 1970 s and 1980 s, the majority of immigrants settled in a few economically vibrant and large metropolitan areas on the West and East coasts which provided them with greater economic opportunities and which had well established immigrant-ethnic communities and low-skilled service sectors. These areas offered a sense of social and economic security to new immigrants, particularly the less educated and the less skilled, who might have found it difficult to get suitable employment or social acceptance elsewhere. However, in response to globalization and international competition during the $1990 \mathrm{~s}$, industrial restructuring became a dominant feature of American economy. As a result, there was a significant shift of many industries (e.g., food processing and construction industries) to rural areas and small towns with lower wage rates. Also, many low-skilled jobs were created in the secondary labour market, which were usually not attractive enough to native-born workers. Immigrant workers not only filled these new jobs, but also created low-cost services (e.g., housekeepers/maids) that would otherwise have disappeared altogether.

The second part of the book includes six chapters which document various consequences of the increasing geographic diversity of immigrants. These chapters move away from the global statistical picture and concentrate on specific geographic regions and communities. Authors of these chapters focus primarily on intergroup relations, xenophobic responses to immigrant settlement in new geographic locations, and the perpetuation of segmented labour markets. They provide ample evidence to show how various groups of lower socioeconomic status-blacks and Hispanics in particular-see themselves as competitors in the secondary labour market. The book concludes with a sombre note about the future course of the adaptation and assimilation of new immigrants in American society, known for its melting-pot model. Although most of the authors appear to present optimistic scenarios about the prospects for assimilation of immigrants as evidenced by a low retention of their mother tongue, significant socioeconomic gains, progress among those who have lived in the United States for longer durations, to Massey "the path of immigrant adaptation may be more difficult than in the past and that worry about the future assimilation is not entirely misplaced" (p. 346). This is certainly a serious challenge for public policy.

One of the strengths of this volume is that it is based on sound theoretical and empirical grounds. All chapters articulate theoretical arguments guided mainly by the tenets of globalization, economic competition, and industrial restructuring and then provide empirical evidence to support them. The authors of the first four chapters make meticulous use of data from the 1980, 1990, and 2000 Censuses, primarily based on Public Use Microdata Samples, to present a global depiction of the emergence of new settlement patterns. Massey and Capoferro (chapter 2) also make use of the Current Population Survey 2005 to portray a more up-to-date picture. While discussing the emergence of new 
nonmetropolitan immigrant gateways, Donato, Tolbert, Nucci and Kawano (chapter 4) analyse confidential and geographically detailed data from the 1990 and 2000 Censuses produced internally within the U.S. Bureau of the Census, which are not normally available to the public. Making use of data from the Louisiana Immigrant Project (1999), Donato and Bankston (chapter 6) go into a much deeper analysis of Hispanic settlement patterns and the emergence of a segmented labour market in Southern Louisiana.

While all chapters in the first part of the book are purely quantitative and global in nature, all chapters in the second part are devoted to a deeper understanding of intergroup relations-especially tensions between African Americans and Hispanic newcomers in specific communities-with judicious use of qualitative techniques such as focus group (chapter 7), case study (chapter 8), ethnographic research (chapters 8 and 9), participant observation (chapters 9 and 10), social-historical analysis (chapter 11), and semi-structured interviews. In-depth analyses of attitudes toward immigrants and social networks in a small Midwestern community (Minnesota), with a large meat-processing plant (chapter 7), a local event such as Kennett Square's (Pennsylvania) Cinco de Mayo festival (chapter 11), and Hotel Nashville (chapter 10) provide interesting examples of the usefulness of qualitative methods, complementing quantitative analyses.

The use of quantitative and qualitative approaches to study immigrant settlement patterns is a noteworthy strength of this volume. However, this is also its major weakness. It is not at all clear why all five chapters in the first part of the book, which deal with determinants of geographic dispersion, use quantitative approaches, while all six chapters in the second part, which deal with the consequences of geographic dispersion use qualitative approaches. While the qualitative approach in the second part was able to capture numerous intricate details of intergroup relations, they lacked breadth and quantitative precision. For example, one infers from various stories told in several chapters that new immigrants take away jobs from native-born workers or depress their earnings, particularly vulnerable groups such as the less educated and the less skilled, because immigrants are generally more tolerant of difficult working conditions, unregulated work environment and lower wages. A reader looking for some kind of quantitative evidence to support this assertion would be disappointed with this volume. Some kind of balance between the two approaches would have made the volume more attractive.

Another limitation of this volume is that virtually every chapter discusses residential patterns of just one immigrant group-Mexican/Hispanic. It is true that this group forms the largest proportion of the foreign-born population in the United States, but immigrants from other countries - particularly from China, Philippines, and India - who have become highly prominent in recent years are given a superficial treatment. It would be interesting and useful to know why the 
geographic diversification is not as evident for these immigrant groups, compared with Mexican immigrants.

Notwithstanding these limitations, this is a commendable attempt by Douglas S. Massey to put such a fine collection of engaging studies together in one volume. The book will certainly be of interest to demographers, human geographers, urban sociologists, and human ecologists concerned with the growth and settlements of immigrants not only in the United States, but also in other industrialized countries which are experiencing industrial restructuring as a result of globalization and where immigrants form a significant proportion of the population. Also, it should be useful to scholars and students who would like to combine quantitative and qualitative approaches to study intergroup relations, particularly the tensions between native-born people of lower socioeconomic status and new immigrants. 